\title{
Streptomyces: implications and interactions in plant growth promotion
}

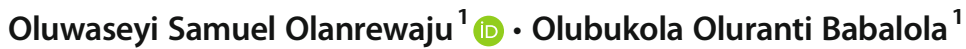

Received: 24 July 2018 / Revised: 10 December 2018 / Accepted: 11 December 2018 / Published online: 29 December 2018

(C) The Author(s) 2018

\begin{abstract}
With the impending increase of the world population by 2050 , more activities have been directed toward the improvement of crop yield and a safe environment. The need for chemical-free agricultural practices is becoming eminent due to the effects of these chemicals on the environment and human health. Actinomycetes constitute a significant percentage of the soil microbial community. The Streptomyces genus, which is the most abundant and arguably the most important actinomycetes, is a good source of bioactive compounds, antibiotics, and extracellular enzymes. These genera have shown over time great potential in improving the future of agriculture. This review highlights and buttresses the agricultural importance of Streptomyces through its biocontrol and plant growth-promoting activities. These activities are highlighted and discussed in this review. Some biocontrol products from this genus are already being marketed while work is still ongoing on this productive genus. Compared to more focus on its biocontrol ability, less work has been done on it as a biofertilizer until recently. This genus is as efficient as a biofertilizer as it is as a biocontrol.
\end{abstract}

Keywords Actinomycetes $\cdot$ Biocontrol $\cdot$ Biofertilizer $\cdot$ Streptomyces $\cdot$ Sustainable agriculture $\cdot$ VOCs

\section{Introduction}

Actinomycetes are Gram-positive bacteria characterized by a genome with high $\mathrm{G}+\mathrm{C}$ ratio. They are mostly aerobic, but some of them can grow anaerobically. Several actinomycetes form branching filaments and possess mycelial growth while some species produce external spores. Out of all rhizosphere microbes, actinomycetes are regarded to be special in plant growth promotion because they exhibit many useful traits (El-Tarabily and Alkhajeh 2016; Monteiro et al. 2017). Their filaments and ability to sporulate help them cleave strongly to the rhizospheric soil particles forming a strong bond with the plants.

Actinomycetes are a numerous and widely distributed group of soil microbes, constituting to about 10 to $50 \%$ of the soil microflora community. Tyc et al. (2017), Adegboye and Babalola (2012), and other researchers have reported them to be important producers of secondary metabolites. The metabolites produced are diversified in their biological

Olubukola Oluranti Babalola

Olubukola.Babalola@nwu.ac.za

1 Food Security and Safety Niche Area, Faculty of Natural and Agriculture Sciences, North-West University, Mmabatho 2735 , South Africa activities and functions such as antifungal, insecticidal, antibacterial, and antihelminthic activities. Actinomycetes, like other plant growth-promoting microbes, also produce phytohormone (Jog et al. 2016), and solubilize phosphate (ElTarabily et al. 2008; El-Tarabily and Sivasithamparam 2006). This goes a long way to show the interest in the use of actinomycetes that can solubilize phosphate in phosphatedeficient soils. As reported by Mercado-Blanco and Bakker (2007), they interact with plants as free-living non-symbiotic bacteria. Despite the fact that they are largely spread in nature and have been strongly studied largely due to their production of numerous antibacterial and antifungal compounds, only a few works have established their importance, for example, wheat (Toumatia et al. 2016) and broccoli (Ruzzi and Aroca 2015). Due to their abundance, they have been isolated from tissues of various plants including wheat, rice, maize, soybean, and pepper (Adegboye and Babalola 2012; El-Tarabily and Alkhajeh 2016; Goudjal et al. 2014; Jog et al. 2016).

Most studied actinomycetes plant growth-promoting species possess antibacterial or antifungal activity which was imminent during their screening as biocontrol agents (Adegboye and Babalola 2012; Jog et al. 2016). To buttress this, many products such as Mycostop (Streptomyces griseoviridis K61), Actinovate (Streptomyces lydicus), and Nogall (Agrobacterium radiobacter Strain K1026) have been produced. Actinomycetes' ability to colonize plant roots, fight 
against pathogens, synthesize extracellular proteins, produce antibiotics, and degrade phytotoxins makes them potent plant growth-promoting agents.

\section{Properties and classifications of actinomycetes}

They include microbes delineating an expanse range of morphologies, from hyphal forms to coccoid including those exhibiting highly variable physiological and metabolic traits. Actinomycetes members have evolved lifestyles differing to that of pathogens as demonstrated by Corynebacterium, Mycobacterium, Nocardia, Tropheryma, and Propionibacterium. They are soil inhabitants (Streptomyces) and gastrointestinal commensals (Bifidobacterium) as well as plant commensals (Leifsonia) (Ventura et al. 2007).

These bacteria resemble fungi in their morphology forming branching hyphae, asexual spores, and mycelium. This means that they have characteristics that are common to both fungi and bacteria; they are actually at the transition between bacteria and fungi. They are abundant and widely distributed in the soil leading to the claim that the characteristic smell of soil is actually due to the actinomycetes present. Some form mutualistic relationships with plants promoting their growth and protecting them from pathogens. In addition, they also form associations with green algae. However, not all actinomycetes are beneficial microbes, some are plant pathogens causing diseases such as potato scab, wilt, and gall, as well as causing diseases in humans and animals. They are classified into different genera based on their physiology and morphology. Based on this, some of the known actinomycetes are Actinomyces, Nocardia, Streptomyces, Thermoactinomyces, Waksmania, Thermopolyspora, Micromonospora, Thermomonospora, Actinoplanes, and Streptosporangium (Babalola et al. 2009). Among the actinomycetes, the Streptomyces genus happens to be the most regarded and well known due to its numerous identified importance. Its importance has been established in health, agriculture, and other important sectors. In this review, emphasis will be on this genus in relation to its plant growth promotion abilities as a biocontrol agent and biofertilizer. We will also consider the strategies common to their actions as plant growth promoters.

\section{Overview of the Streptomyces genus}

Streptomyces are important groups of soil bacteria from the actinomycetes family. Alongside Micromonospora, they are the most commonly described actinomycetes making up 1$20 \%$ of the culturable soil microbes. The colony growth of Streptomyces becomes visible when a spore germinates and produces long filaments which have multiple nuclei (van
Dissel et al. 2014). The filaments elongate by apical growth and branch repeatedly producing a substrate mycelium that develops both on the culture medium and into it. The hyphae, which are formed by the mycelium, penetrate the medium in the presence of extracellular hydrolytic enzymes solubilizing organic molecules present. The filaments allow for efficient use of nutrients in the rhizosphere and it also enables the Streptomyces to colonize substrates better than unicellular microorganisms. Cell interactions are important in governing multicellular development and cellular differentiation in the Streptomyces colony (Miguélez et al. 2010). At the latter stage when the colony is getting old and the nutrients are exhausted, specialized branches evolve from the surface of the colony which results in the aerial mycelium (reproductive) that grows vertically into the air (Hu et al. 2012). Advances in sequencing technology have revealed significant findings which have helped in understanding the mechanisms involved at different transition stages of Streptomyces life cycle although the focus has mainly been on single-species cultures. On the other hand, same growth level cannot be recorded in the laboratory for any individual soil microbe because the laboratory environment may not capture the full potential of these microbes due to the difference in environmental conditions and the satiated level of microbes in the soil.

An extremely important and notable characteristic of Streptomyces is the ability to carry out a complex life cycle that can phylogenetically be considered as one of the probably several pioneer attempts at multicellular transformations and evolvement (Jones and Elliot 2017). They act in the catabolism of complex molecules and substances like lignocellulose, xylan, cellulose, and lignin, which are important in soil organic matter catabolism.

Streptomyces is one of the major sources of bioactives known and they are majorly studied for this reason (Tom et al. 2016). Some of the bioactives include secondary metabolite production, in the form of antibiotics and extracellular enzymes not forgetting antitumor and agroactive compounds which are important in the decomposition of cellulose and chitin (Adegboye and Babalola 2012; Tyc et al. 2017).

Approximately two thirds of natural antibiotics have been isolated from actinomycetes, and about $75 \%$ of them are from the Streptomyces genus (Franco-Correa et al. 2010). It is also reported by Berdy (2005) that Streptomyces produce about 7600 bioactive compounds. This has made Streptomyces become the major antibiotic producer used for drug discovery and production in the pharmaceutical industries (Kumari et al. 2017; Shekh and Naim 2017). Most Streptomyces produce some minute amount of $\alpha$-butyrolactones, which is analogous to homoserine lactones, and have been deduced to play an important role as signals and markers for the setting-in of morphological and physiological differentiation (Safari et al. 2014). $\alpha$-Butyrolactone, which is present in most Streptomyces, was the first Streptomyces sporulation factor 
discovered. It was first characterized as an activator of streptomycin production and spore formation in Streptomyces griseus (Miguélez et al. 2010).

\section{Plant growth-promoting Streptomyces (PGPS)}

Most Streptomyces are efficient rhizosphere and rhizoplane colonizers. They can also be endophytes colonizing inner tissues of host plants (Sousa and Olivares 2016). These attributes may be due to features such as quorum sensing controlled gene expression, multiplication rate, antibiotics, siderophore, cellulases, phytohormones, amino acid synthesis, chitinase, lipase, and $\beta$-1,3-glucanase production. Exudate attraction of Streptomyces to the rhizosphere is accomplished by the chemotaxis movement of these microbes.

In the agricultural sector, the emergence of PGPS either as biofertilizer or biocontrol has led to new discoveries into other ways these microbes can be useful. Streptomyces are not left out in this discovery, although many studies have focused on the biocontrol activities of these genera due to its high production of bioactive compounds which are used as defense mechanisms.

\section{PGPS as a biocontrol agent}

The global attempts to discovering natural products as biocontrol agents for plant protection have notably been on the rise and actinomycetes, Streptomyces being the most proactive, appear to be a readily available natural choice in finding new ways to combat plant pathogens.

Their abilities to control plant pathogens stem from the following traits:

- Synthesis of plant growth regulators (Goudjal et al. 2013)

- Siderophore production (Vijayabharathi et al. 2015)

- Antibiotics production (Couillerot et al. 2013)

- Volatile compound secretion (Jones and Elliot 2017) and

- Competition for nutrients

Its main biocontrol ability is attributed to its strong production of antibiotics, volatile compounds, and other metabolites which help in its role as antipathogens, e.g., siderophores from S. coelicolor (Som et al. 2017), chitinase from S. violaceusniger YH27A strain (Gherbawy et al. 2012), as well as the antifungal nigericin, and antibiotic geldanamycin from S. violaceusniger YCED-9 (Shrivastava and Kumar 2018). These compounds are attributed to hypha development activated by a nutrient deficit. Their biological activities are well described in the works of Al-Askar et al. (2015), Errakhi et al. (2016), and Shekh and Naim (2017). In like manner, they are also regarded as stress metabolites because of their role in adaptivity during stress. Production of these metabolites involves the actions of some genes that exist majorly in clusters. It is in these clusters that regulatory proteins and phosphorylated guanosine nucleotide phosphate (ppGpp) (which is an important protein for metabolite synthesis) are encoded (Sivapragasam et al. 2017). Nutritional stress activates alarmone ppGpp which regulates antibiotic production. Streptomyces antibiotic regulatory proteins and lysosomal acid lipase families, which are species specific, are also important in metabolism pathway regulations. The type of signals sent and received by a Streptomyces determines the metabolites produced. Nutrient deficit sends a signal, pathogen attack also activates a signal, etc. In PGPS cell-cell communication, $\alpha$-butyrolactones are the major signaling molecules. Some Streptomyces exhibiting biocontrol activities against some known plant pathogens are shown in Table 1.

Pathogen-antagonistic PGPS were also used to promote the growth of coniferous plants. In Brazil, there was the report of an isolate close to Streptomyces kasugaensis which was shown to inhibit the growth of Fusarium and Armillaria pine rot and it also showed plant growth promotion abilities on Pinus taeda seedlings under greenhouse experiment (de Vasconcellos and Cardoso 2009). Studies of El-Abyad et al. (1993) also showed the use of Streptomyces pulcher, Streptomyces canescens, and Streptomyces citreofluorescens in biocontrol of diseases caused by Fusarium oxysporum, Verticillium albo atrum, Alternaria solani, Pseudomonas solanacearum, and Clavibacter michiganensis subsp. michiganensis in tomatoes. It was reported that tomato growth was significantly improved. Another example was observed evident in the study conducted by Tokala et al. (2002) with the Streptomyces lydicus strain WYEC 108 in both growth chamber and greenhouse experiments. The result of this study was later used in the formulation and the commercialization of Actinovate $^{\circledR}$ and Actino-Iron ${ }^{\circledR}$, a well-known biocontrol product because of its unique traits (Crawford et al. 2005). It was observed that there was an increase in shoot and root length, and root wet weights in pea seedlings. There was also an increase in root nodulation, nodule size, and number of Rhizobium spp. As this was feasible in the more numerous and vigorous nodules found in PGPS-colonized plants than in the control plant, an increase in the number of bacteria per nodule, nitrogenase activity, and nodular assimilation of iron was also observed (Tokala et al. 2002). This is also supported by the work of Hoster et al. (2005). This ability is due to the production of antibiotics and enzymes (such as the chitinolytic enzymes) to inhibit pathogens, and of plant growth-promoting compounds like phytohormones, solubilization of phosphates, and competition with plant pathogens for substrates and nutrients (Charousová et al. 2016; de Vasconcellos and Cardoso 2009; Kinkel et al. 2012).

PGPS has also been widely used in the biocontrol of soilborne fungal pathogens (Gopalakrishnan et al. 2013). The biocontrol ability against numerous phytopathogens 
Table 1 Biocontrol and plant growth-promoting activities of some PGPS

\begin{tabular}{|c|c|c|c|}
\hline & PGPS & Elicited effects & References \\
\hline \multirow[t]{8}{*}{ Biocontrol activities } & Streptomyces griseus & Rhizoctonia solani & Merriman et al. (1974) \\
\hline & Streptomyces kasugaensis & \multirow[t]{2}{*}{ Fusarium sp. } & de Vasconcellos and Cardoso (2009) \\
\hline & Streptomyces J-2 & & Errakhi et al. (2016) \\
\hline & Streptomyces sp. & Sclerotium rolfsii & Gholami et al. (2014) \\
\hline & Streptomyces sanglieri & Ganoderma boninense & Azura et al. (2016) \\
\hline & Streptomyces griseorubens E44G & \multirow{2}{*}{$\begin{array}{l}\text { Fusarium oxysporum f. sp. } \\
\quad \text { lycopersici }\end{array}$} & Al-Askar et al. (2015) \\
\hline & Streptomyces rochei ACTA1551 & & Kanini et al. (2013) \\
\hline & Streptomyces felleus YJ1 & Sclerotinia sclerotiorum & Cheng et al. (2014) \\
\hline \multirow{7}{*}{$\begin{array}{l}\text { Plant growth-promoting } \\
\text { activities }\end{array}$} & \multirow{3}{*}{$\begin{array}{l}\text { Streptomyces anulatus S37 } \\
\text { Streptomyces sp. }\end{array}$} & \multirow{4}{*}{$\begin{array}{l}\text { Grapevine } \\
\text { Bean } \\
\text { Chickpea }\end{array}$} & Couillerot et al. (2013) \\
\hline & & & Jarak et al. (2012) \\
\hline & & & Gopalakrishnan et al. (2015) \\
\hline & $\begin{array}{l}\text { Streptomyces matansis BG5, } \\
\text { Streptomyces } \mathrm{sp} \text {. RSF17, } \\
\text { Streptomyces vinaceus } \mathrm{CRF} 2 \text {, } \\
\text { Streptomyces } \mathrm{sp} \text {. CRF14, } \\
\text { Streptomyces pulcher CRF17, } \\
\text { Streptomyces griseoincarnatus } \mathrm{SCF} 18\end{array}$ & & Javaid and Sultan (2013) \\
\hline & Streptomyces PRIO41 & Pepper & Robles-Hernández et al. (2015) \\
\hline & Streptomyces mutabilis & Wheat & Toumatia et al. (2016) \\
\hline & Streptomyces fumanus gn-2 & Soybean & Doolotkeldieva et al. (2015) \\
\hline
\end{tabular}

Fusarium oxysporum, Penicillium digitatum, and Sclerotium rolfsii among others is well documented (Al-Askar et al. 2015; Priya et al. 2017). Their secondary metabolite-producing ability is the most important property of this genus in carrying out their biocontrol activities.

\section{PGPS as biofertilizer}

Despite their popularity as biocontrol agents, their functioning as biofertilizers has been partly understudied. Being one of the most abundant microbes in the microflora, and considering their effectiveness in plant root system colonization, it is surprising that they have not been adequately studied for plant growth promotion. They directly promote plant growth by the production of phytohormones (auxins, cytokinins, and gibberellins), siderophores scavenge ferric iron from the environment, nitrogen fixation and, suppression of stress in plant by production of 1-aminocyclopropane-1-carboxylate (ACC) deaminase activity (Sadeghi et al. 2012; Verma et al. 2011). The use of Streptomyces griseus in plant growth was reported by Merriman et al. (1974). In the work, the isolate was originally meant to serve as biocontrol but it was found out to have a tremendous effect on grain yield, dry foliage weight, tiller number, and advanced head emergence for both wheat and oat over controls especially when applied on carrots. Biocontrol efficacy of Streptomyces sp. against bacterial, Fusarium and Verticillium wilts in tomato was also reported by El-Abyad et al. (1993). In the study, tomato growth was significantly observed to improve due to the growth regulators produced by the inoculum. The release of phosphate through the actions of released malic acid and gluconic acids by Streptomyces mhcr0816 and Streptomyces mhce0811 respectively was reported in the study of Jog et al. (2014). Like most rhizobacteria, they are capable of directly affecting the growth of plants positively. Other works on PGPS acting as plant growth promoters on different crops are shown in Table 1.

\section{Specific mechanisms of PGPS which can be exploited for plant growth promotion}

A new discovery was made as a result of the interaction between PGPS and various yeast species. The co-culture resulted in a previously unknown reaction in PGPS cultures. This reaction which is glucose-repressible was called exploratory growth behavior by the PGPS which occurs as a result of deficient glucose in the PGPS-yeast environment. This means that glucose deficiency activates PGPS exploration through yeast stimulation (Jones et al. 2017). A rapid outgrowth of vegetative hyphae is a characteristic of exploratory growth behavior as observed in $S$. venezuelae which was estimated to be approximately $90 \mathrm{~mm} \mathrm{~h}^{-1}$ (Jones et al. 2017). On a closer look, the exploring hyphae do not seem to branch which may contribute to the spreading of the exploring PGPS colonies. This outward spreading is an advantage in the organism dominating its immediate environment by taking more space, while in the rhizosphere, the colony is able to outcompete 
other microbes through this exploratory growth mechanism. Perhaps, this might be the reason for its abundance compared to other soil microbes.

Aside from the exploratory growth mechanism, PGPS use volatile organic compounds (VOCs) to modulate environmental conditions through their actions as signals. These signals can result in regulating gene expression of surrounding microbes. They can act as elicitors of gene activation or repression as well as determine the response of other microbes in the soil environment. Furthermore, VOCs along with trimethylamine act as antibacterial and antifungal agents. Both Micrococcus luteus and Bacillus subtilis were being inhibited by the synergy of PGPS and trimethylamine (Jones et al. 2017). Trimethylamine raises the $\mathrm{pH}$ of the environment to a level that is not conducive to other microbes thereby affecting the transmembrane $\mathrm{pH}$ and proton motive forces.

\section{Identification of candidate PGPS}

Most Streptomyces species can be wrongly misjudged as good plant growth promoters based on their ability to produce metabolites. In most cases, these metabolites are virtually not important because they have not been proven to be useful in anyway. Again, not all metabolites produced are actually good for the plants, some are actually deleterious to plant health. In view of this, we briefly propose a "check" to identify important PGPS taking into consideration time factor, cost of experiments, and purpose of experiment.

One of the most important traits of a good plant growth promoter is root colonization (Bhattacharyya and Jha 2012; Olanrewaju et al. 2017). Although it has been reported that Streptomyces are good root colonizers, some are not and the degree also varies from one species to another. Before a species can be selected as a plant growth-promoting agent, the level of root colonization must be ascertained. It must be able to compete favorably well against other microbes to be able to exert its influence on the host plants.

We cannot underestimate the importance of the metabolites these species produce. As said earlier, not all metabolites have positive impacts. Using advanced tools and technologies, the genetic makeup and gene expression level in the organisms can be studied. Knowing this will help identify important genes, metabolites, and invariably functions of these genes. This can be made possible through the application of functional genomics and system biology. Cost and time have to be taken into consideration in this regard. Although advent of next generation sequencing (NGS) has substantially reduced the cost of sequencing, not all researchers can still afford to spend that amount on testing an organism. Since most Streptomyces genes are in clusters, these clusters can be identified including their mode of regulations. In Table 2, we can find examples of some species, their metabolites, and the gene locations.
Molecular markers can also be useful in this case. Regions coding for important traits that are valuable in the Streptomyces can easily be mapped and studied. Various molecular markers have been developed such as restriction fragment length polymorphism (RFLP), small nucleotide polymorphism (SNP), and diversity array technology (DArT) markers.

Application of NGS technology with molecular markers can be used in the identification of gene clusters present in Streptomyces. Once clusters can be correctly identified then the genes present in these clusters will definitely be known. Once known, functions of each gene can be known through functional genomics, proteomics, transcriptomics, and other omics technologies. Interactomics can be applied to know the interactions between the genes and subsequent responses to these interactions. The studies of these interactions can open up the pathway for the synthesis of the major bioactive compounds produced by each species in response to various interactions.

\section{PGPS: antibiotic resistance, safety, and mode of application}

Antibiotics are used to control invading microbes in humans, plants, and animals. Majority of these antibiotics are gotten from the Streptomyces genus. In the soil, these genera are relatively dominant. These antibiotics when secreted by soil Streptomyces help ward off invading pathogens. Not all antibiotics released are actually safe for the plants they are meant to protect. Some are actually deleterious to the plants. Effects of antibiotics on the environment are not yet well ascertained. On plants, toxicity of some antibiotics has been assayed and various negative and positive impacts have been recorded both on the plants and the soil. Variations were also observed in the activities of some antibiotics toward various plants as seen in the plant growth promotion of tetracycline on radish yields and the same antibiotics decreasing pinto yield (Batchelder 1982). The current interest of cutting down on chemical fertilizer use has increased the use of plant growthpromoting rhizobacteria (PGPR) as alternatives.

Development of antibiotic resistance in various sectors such as health, agriculture, and environment has led to some researchers suggesting the possibility of pathogens becoming resistant to PGPS. Since the basic mode of action of these PGPS against pathogens is the production of antibiotics and they are the largest producers of antibiotics, any development of resistance to these strains will have great impact on health and agricultural sectors. Pathogens can adapt to the antibiotics after long and frequent interactions by developing resistance. According to Martínez (2008), the release of a large amount of antibiotics might change the rhizosphere population dynamics as well as selection of resistance. This notably implies that concentration of the antibiotics in contact with the pathogens 


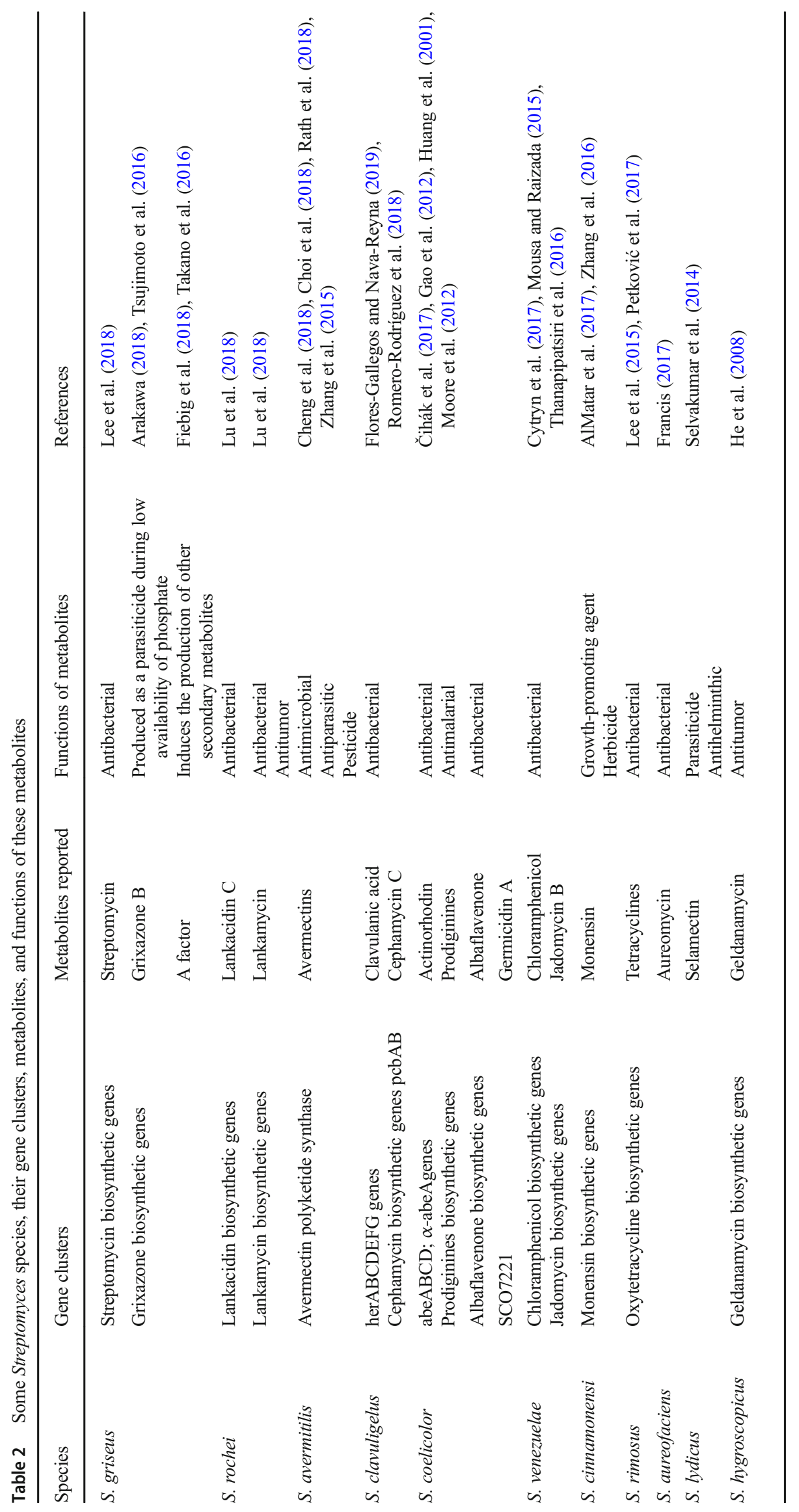


in the rhizosphere is key to the development of resistance. In as much as no concrete evidence have evolved concerning development of antibiotic resistance toward PGPS, there can be transfer of genes (horizontal and lateral) among various individuals in the rhizosphere. With this in mind, there is the possibility of these pathogens picking up resistance genes and thereby eliciting resistance against the particular antibiotics. This is so very possible but it is not enough to suggest that the pathogen will therefore be able to resist the PGPS because PGPS do not release only one type of antibiotics. If the pathogen develops resistance to a particular antibiotic, there are many more that will act against the pathogen either from the same PGPS or other PGPS present in the rhizosphere. In addition to antibiotics, PGPS and other biocontrol agents produce enzymes and various volatile compounds that are used as mechanisms of biocontrol.

Due to some of the metabolites produced, some safety concerns have been raised. Safety to the plants and humans to exposure to PGPR interactions is becoming a concern in certain quarters. No health issues either to plants or humans have been reported as a result of the use of any PGPR. Although various metabolites are produced as biocontrol agents, none of these have been associated with any negative effect on plants. Most metabolites causing diseases are from pathogens. An example is seen in pyocyanin which is produced by Pseudomonas aeruginosa, an opportunistic plant and human pathogen (Schroth et al. 2018; Stover et al. 2000). They are also regarded as plant growth promoters but they have been reported to induce growth of some plants (Tiwari and Singh 2017).

Most experiments on PGPR focus on the use of the microbes other than their products. This is better because it is these microbes that release the metabolites that are used as biocontrol agents or as growth promoters. As part of their mechanisms of actions, they produce antibiotics, volatile compounds, auxins, gibberellins, cytokinins, ethylene, enzymes, etc. (Olanrewaju et al. 2017), which are used in plant growth promotion. Some research have focused on using some of these antibiotics directly on plants against pathogens and for plant growth promotion (Devireddy et al. 2017; Minden et al. 2017). The use of these antibiotics directly on soil can increase the rise of resistance in the soil (Cadena et al. 2018; Zhang et al. 2017). It is safer to use the PGPRs instead of their products as no negative effect have been recorded from their use. Application of the PGPR directly will also mean that all other mechanisms in the PGPR will be available for the plant use than selected metabolites which will act singly.

\section{Conclusion and recommendations}

Using plant growth-promoting bacteria to improve nutrient availability, biosynthesize metal chelators and phosphorus solubilizers, produce phytohormones, control phytopathogens, and alleviate abiotic stress in plants is an important practice for sustainable agriculture and also a good alternative to environmentally hazardous chemical fertilizers and pesticides (Olanrewaju et al. 2017). Except for few cases, PGPR are safe to the plants and humans.

The importance of Streptomyces strains in plant growth promotion is vividly expressed in their antipathogenic activities. Their metabolic potential should be a strong area to be looked at by researchers as it is paramount to majority of the plant growth promotion traits that have been discussed in this review. It is of little surprise that this rich source of bioactive compound-producing microbes has been underutilized so to say in agriculture. We believe that these microbes should be considered a great weapon in the search for viable plant growth promoters for sustainable agriculture.

Aside from trimethylamine, other VOCs produced by Streptomyces should be ascertained for their ability to alter environment $\mathrm{pH}$ as this might be another area to explore in biological control. More Streptomyces strains can be cultured and exploited toward their VOC production. VOCs represent a largely untapped class of metabolites, and further work will be required to fully appreciate the ecological roles of these compounds and agricultural potential.

Exploration by Streptomyces can also be targeted as it allows for a rapid and vast area covering by the organism which enhances closeness to the nutrient source. Communication has also been established by the production of certain VOCs. As discussed earlier, exploration results from interaction through the glucose-deficient phenomenon which means that different interactions when studied might pave way for new developments to be discovered which might be helpful in plant-microbe and microbe-microbe interactions for effective plant growth promotion.

The overall adaptive traits of the Streptomyces genus which make it possible to exist in a wide range of both aquatic and terrestrial environments can be attributed to the formation of spores. This trait gives it a greater edge over other microorganisms. The ecophysiological significance of the interactions between the genus and various parts of plants which confers its plant growth promotion traits should be well studied to vividly elucidate the mechanism involved.

Most of the activities of the Streptomyces genus come from its ability to produce secondary metabolites; therefore, mechanisms involved in the regulation and production of these metabolites as well as the regulation of the gene clusters should be well studied with the advent of next-generation sequencing and advancement in bioinformatics. Omics approaches will definitely contribute to the existing knowledge on Streptomyces rhizosphere colonization, crosstalk between the genus, and other organisms in the rhizosphere, etc. 
Finally, research into bioinoculants formulation involving carriers, additives, and optimum delivery methods will increase the chances of these organisms to survive when introduced into the environment thereby increasing their acceptability.

There is no precise means to differentiate plant growthpromoting microbes as some microbes are termed as plant growth promoters and pathogens. Example of such is Pseudomonas aeruginosa that has been reported as both plant growth promoter and pathogen (Tiwari and Singh 2017). There should be a clarity between these two groups as they can all be found in the rhizosphere and endosphere of plants. Research should be directed toward better understanding and differentiation of these groups.

Although no report has emerged of pathogens being resistant to any biocontrol agent, control measures should be put in place as a check.

Funding information North-West University is gratefully acknowledged for a school bursary to OOS. OOB would like to thank the National Research Foundation, South Africa for grants (Ref: UID81192, UID98460, UID104015, UID104050) that have supported research in her laboratory.

\section{Compliance with ethical standards}

Conflict of interest The authors declare that they have no conflict of interest.

Ethical approval This article does not contain any studies with human participants or animals performed by any of the authors.

OpenAccess This article is distributed under the terms of the Creative Commons Attribution 4.0 International License (http://creativecommons.org/ licenses/by/4.0/), which permits unrestricted use, distribution, and reproduction in any medium, provided you give appropriate credit to the original author(s) and the source, provide a link to the Creative Commons license, and indicate if changes were made.

Publisher's Note Springer Nature remains neutral with regard to jurisdictional claims in published maps and institutional affiliations.

\section{References}

Adegboye MF, Babalola OO (2012) Taxonomy and ecology of antibiotic producing actinomycetes. Afr J Agric Res 7(15):2255-2261

Al-Askar AA, Baka ZA, Rashad YM, Ghoneem KM, Abdulkhair WM, Hafez EE, Shabana YM (2015) Evaluation of Streptomyces griseorubens E44G for the biocontrol of Fusarium oxysporum $\mathrm{f}$. sp. lycopersici: ultrastructural and cytochemical investigations. Ann Microbiol 65(4):1815-1824

AlMatar M, Eldeeb M, Makky EA, Köksal F, Var I, Kayar B (2017) Are there any other compounds isolated from Dermacoccus spp at all? Curr Microbiol 74(1):132-144

Arakawa K (2018) Manipulation of metabolic pathways controlled by signaling molecules, inducers of antibiotic production, for genome mining in Streptomyces spp. Antonie Van Leeuwenhoek:1-9
Azura AN, Yusoff M, Tan G, Jegadeesh R, Appleton D, Vikineswary S (2016) Streptomyces sanglieri which colonised and enhanced the growth of Elaeis guineensis Jacq. seedlings was antagonistic to Ganoderma boninense in in vitro studies. J Ind Microbiol Biotechnol 43(4):485-493

Babalola OO, Kirby BM, Roes-Hill L, Cook AE, Cary SC, Burton SG, Cowan DA (2009) Phylogenetic analysis of actinobacterial populations associated with Antarctic Dry Valley mineral soils. Environ Microbiol 11(3):566-576

Batchelder A (1982) Chlortetracycline and oxytetracycline effects on plant growth and development in soil systems 1. J Environ Qual 11(4):675-678

Berdy J (2005) Bioactive microbial metabolites. J Antibiotics 58(1):1-26

Bhattacharyya PN, Jha DK (2012) Plant growth-promoting rhizobacteria (PGPR): emergence in agriculture. World J Microbiol Biotechnol 28(4):1327-1350

Cadena M, Durso LM, Miller DN, Waldrip HM, Castleberry BL, Drijber RA, Wortmann C (2018) Tetracycline and sulfonamide antibiotic resistance genes in soils from Nebraska organic farming operations. Front Microbiol 9:1283

Charousová I, Javoreková S, Medo J, Schade R (2016) Characteristic of selected soil Streptomycetes with antimicrobial potential against phytopathogenic microorganisms. J Microbiol Biotechnol Food Sci 5(64):64-68

Cheng G, Huang Y, Yang H, Liu F (2014) Streptomyces felleus YJ1: potential biocontrol agents against the sclerotinia stem rot (Sclerotinia sclerotiorum) of oilseed rape. J Agric Sci 6(4):91

Cheng Y, Yang R, Lyu M, Wang S, Liu X, Wen Y, Song Y, Li J, Chen Z (2018) IdeR, a DtxR-family iron-response regulator, controls iron homeostasis, morphological differentiation, secondary metabolism, and oxidative stress response in Streptomyces avermitilis. Appl Environ Microbiol:AEM. 01503-18

Choi H-Y, Van Minh N, Choi JM, Hwang JY, Seo S-T, Lee S-K, Kim WG (2018) Enzymatic synthesis of avermectin B 1a glycosides for the effective prevention of the pine wood nematode Bursaphelenchus xylophilus. Appl Microbiol Biotechnol 102(5):2155-2165

Čihák M, Kameník Z, Šmídová K, Bergman N, Benada O, Kofroňová O, Petrríčková K, Bobek J (2017) Secondary metabolites produced during the germination of Streptomyces coelicolor. Front Microbiol 8(2495). https://doi.org/10.3389/fmicb.2017.02495

Couillerot O, Vatsa P, Loqman S, Ouhdouch Y, Jane H, Renault J-H, Clément C, Barka EA (2013) Biocontrol and biofertilizer activities of the Streptomyces anulatus S37: an endophytic actinomycete with biocontrol and plant-growth promoting activities. IOBC-WPRS Bull 86:271-276

Crawford D, Kowalski M, Roberts M, Merrell G, Deobald L (2005) Discovery, development, and commercialization of a microbial antifungal biocontrol agent, Streptomyces lydicus WYEC108: history of a decade long endeavor. Soc Ind Microbiol News 55:88-95

Cytryn E, Markiewicz Z, Popowska M (2017) Antibiotics and antibiotics resistance genes dissemination in soils antibiotics and antibiotics resistance genes in soils. Springer, pp 145-184

de Vasconcellos RLF, Cardoso EJBN (2009) Rhizospheric streptomycetes as potential biocontrol agents of Fusarium and Armillaria pine rot and as PGPR for Pinus taeda. BioControl 54(6):807-816

Devireddy AR, Inupakutika MA, Willmon D, Kakarla P, Puppala N, Cho Y (2017) Veterinary antibiotics influence trigonelline biosynthesis and plant growth in Arachis hypogaea L. Acta Agric Scand Sect B Soil Plant Sci 67(3):245-251

Doolotkeldieva T, Bobusheva S, Konurbaeva M (2015) Effects of Streptomyces biofertilizer to soil fertility and rhizosphere's functional biodiversity of agricultural plants. Adv Microbiol 5(07):555-571

El-Abyad M, El-Sayed M, El-Shanshoury A, El-Sabbagh SM (1993) Towards the biological control of fungal and bacterial diseases of tomato using antagonistic Streptomyces spp. Plant Soil 149(2):185-195

El-Tarabily K, Alkhajeh A field performance of endophytic actinomycetes in relation to plant growth promotion and biological control of 
Fusarium oxysporum a pathogen of tomato. In, 2016 2016. vol 106. Amer phytopathological soc 3340 pilot knob road, St Paul, MN 55121 USA, p 55-55

El-Tarabily KA, Sivasithamparam K (2006) Non-streptomycete actinomycetes as biocontrol agents of soil-borne fungal plant pathogens and as plant growth promoters. Soil Biol Biochem 38(7):1505-1520

El-Tarabily KA, Nassar AH, Sivasithamparam K (2008) Promotion of growth of bean (Phaseolus vulgaris L.) in a calcareous soil by a phosphate-solubilizing, rhizosphere-competent isolate of Micromonospora endolithica. Appl Soil Ecol 39(2):161-171

Errakhi R, Bouteau F, Barakate M, Lebrihi A, Compant S, Mathieu F (2016) Isolation and characterization of antibiotics produced by Streptomyces J-2 and their role in biocontrol of plant diseases, especially grey mould. Biocontrol of Major Grapevine Diseases: Leading Research:76

Fiebig D, Storka J, Roeder M, Meyners C, Schmelz S, Blankenfeldt W, Scrima A, Kolmar H, Fuchsbauer HL (2018) Destructive twisting of neutral metalloproteases: the catalysis mechanism of the Dispase autolysis-inducing protein from Streptomyces mobaraensis DSM 40487. FEBS J 285(22):4246-4264

Flores-Gallegos AC, Nava-Reyna E (2019) Plant growth-promoting microbial enzymes. Enzymes in food biotechnology. Elsevier, pp 521-534

Francis D (2017) Antimicrobials from microbes. In: Sugathan S, Pradeep NS, Abdulhameed S (eds) Bioresources and bioprocess in biotechnology, vol 2. Springer, Singapore, pp 291-326

Franco-Correa M, Quintana A, Duque C, Suarez C, Rodríguez MX, Barea J-M (2010) Evaluation of actinomycete strains for key traits related with plant growth promotion and mycorrhiza helping activities. Appl Soil Ecol 45(3):209-217

Gao C, Mulder D, Yin C, Elliot MA (2012) Crp is a global regulator of antibiotic production in Streptomyces. MBio 3(6):e00407-e00412

Gherbawy Y, Elhariry H, Altalhi A, El-Deeb B, Khiralla G (2012) Molecular screening of Streptomyces isolates for antifungal activity and family 19 chitinase enzymes. J Microbiol 50(3):459-468

Gholami M, Khakvar R, Niknam G (2014) Introduction of some new endophytic bacteria from Bacillus and Streptomyces genera as successful biocontrol agents against Sclerotium rolfsii. Arch Phytopathol Plant Protect 47(1):122-130

Gopalakrishnan S, Srinivas V, Sree Vidya M, Rathore A (2013) Plant growth-promoting activities of Streptomyces $s p$. in sorghum and rice. SpringerPlus 2:574. https://doi.org/10.1186/2193-1801-2-574

Gopalakrishnan S, Srinivas V, Alekhya G, Prakash B, Kudapa H, Rathore A, Varshney RK (2015) The extent of grain yield and plant growth enhancement by plant growth-promoting broad-spectrum Streptomyces sp. in chickpea. SpringerPlus 4(1):1-10

Goudjal Y, Toumatia O, Sabaou N, Barakate M, Mathieu F, Zitouni A (2013) Endophytic actinomycetes from spontaneous plants of Algerian Sahara: indole-3-acetic acid production and tomato plants growth promoting activity. World J Microbiol Biotechnol 29(10): 1821-1829

Goudjal Y, Toumatia O, Yekkour A, Sabaou N, Mathieu F, Zitouni A (2014) Biocontrol of Rhizoctonia solani damping-off and promotion of tomato plant growth by endophytic actinomycetes isolated from native plants of Algerian Sahara. Microbiol Res 169(1):59-65

He W, Lei J, Liu Y, Wang Y (2008) The LuxR family members GdmRI and GdmRII are positive regulators of geldanamycin biosynthesis in Streptomyces hygroscopicus 17997. Arch Microbiol 189(5):501-510

Hoster F, Schmitz JE, Daniel R (2005) Enrichment of chitinolytic microorganisms: isolation and characterization of a chitinase exhibiting antifungal activity against phytopathogenic fungi from a novel Streptomyces strain. Appl Microbiol Biotechnol 66(4):434-442

Hu J-B, Chen Y-C, Urban PL (2012) On-target labeling of intracellular metabolites combined with chemical mapping of individual hyphae revealing cytoplasmic relocation of isotopologues. Anal Chem 84(11):5110-5116

Huang J, Lih C-J, Pan K-H, Cohen SN (2001) Global analysis of growth phase responsive gene expression and regulation of antibiotic biosynthetic pathways in Streptomyces coelicolor using DNA microarrays. Genes Dev 15(23):3183-3192

Jarak M, Jafari T, Djuric S, Varga J, Cervenski J, Vasic M, Colo J (2012) Plant growth-promoting rhizobacteria in bean production. Acta Hortic 960:409-415

Javaid M, Sultan S (2013) Plant growth promotion traits and Cr (VI) reduction potentials of $\mathrm{Cr}$ (VI) resistant Streptomyces strains. J Basic Microbiol 53(5):420-428

Jog R, Pandya M, Nareshkumar G, Rajkumar S (2014) Mechanism of phosphate solubilization and antifungal activity of Streptomyces spp. isolated from wheat roots and rhizosphere and their application in improving plant growth. Microbiol 160(4):778-788

Jog R, Nareshkumar G, Rajkumar S (2016) Enhancing soil health and plant growth promotion by actinomycetes. Springer, pp 33-45

Jones SE, Elliot MA (2017) Streptomyces exploration: competition, volatile communication and new bacterial behaviours. Trends Microbiol 25(7):522-531

Jones SE, Ho L, Rees CA, Hill JE, Nodwell JR, Elliot MA (2017) Streptomyces exploration is triggered by fungal interactions and volatile signals. Elife 6:e21738

Kanini GS, Katsifas EA, Savvides AL, Karagouni AD (2013) Streptomyces rochei ACTA1551, an indigenous Greek isolate studied as a potential biocontrol agent against Fusarium oxysporum $\mathrm{f}$. sp. lycopersici. Biomed Res Int 2013:387230-387230

Kinkel LL, Schlatter DC, Bakker MG, Arenz BE (2012) Streptomyces competition and co-evolution in relation to plant disease suppression. Res Microbiol 163(8):490-499

Kumari KS, Kalyani P, Vineela KC, Hemalatha V, Hemalatha KPJ (2017) Isolation of antibiotic producing actinomycetes from untapped soils of Yarada hills and assessment of their antimicrobial activities. IJSRET 3(2):290-293

Lee MY, Kim HY, Lee S, Kim J-G, Suh J-W, Lee CH (2015) Metabolomics-based chemotaxonomic classification of Streptomyces spp. and its correlation with antibacterial activity. J Microbiol Biotechnol 25(8):1265-1274

Lee L-H, FASc C, Gan K, Stach J, Wellington EM, Goh BH (2018) The search for biological active agent (s) from actinobacteria. Front Microbiol 9:824

Lu C, Li J-M, Qi H, Zhang H, Zhang J, Xiang W-S, Wang J-D, Wang X-J (2018) Two new lankacidin-related metabolites from Streptomyces sp. HS-NF-1178. J Antibiot 71(3):397-401

Martínez JL (2008) Antibiotics and antibiotic resistance genes in natural environments. Sci 321(5887):365-367

Mercado-Blanco J, Bakker PA (2007) Interactions between plants and beneficial Pseudomonas spp.: exploiting bacterial traits for crop protection. Antonie Van Leeuwenhoek 92(4):367-389

Merriman P, Price R, Kollmorgen J, Piggott T, Ridge E (1974) Effect of seed inoculation with Bacillus subtilis and Streptomyces griseus on the growth of cereals and carrots. Crop Pasture Sci 25(2):219-226

Miguélez EM, Hardisson C, Manzanal MB (2010) Streptomycetes: a new model to study cell death. Int Microbiol 3(3):153-158

Minden V, Deloy A, Volkert AM, Leonhardt SD, Pufal G (2017) Antibiotics impact plant traits, even at small concentrations. AoB Plants 9(2):1-19

Monteiro P, Borba MP, Van Der Sand ST (2017) Evaluation of the antifungal activity of Streptomyces sp. on Bipolaris sorokiniana and the growth promotion of wheat plants. J Agric Sci 9(12):229

Moore JM, Bradshaw E, Seipke RF, Hutchings MI, McArthur M (2012) Use and discovery of chemical elicitors that stimulate biosynthetic gene clusters in Streptomyces bacteria methods in enzymology. Vol 517. Elsevier, pp 367-385 
Mousa WK, Raizada MN (2015) Biodiversity of genes encoding anti-microbial traits within plant associated microbes. Front Plant Sci 6:231

Olanrewaju OS, Glick BR, Babalola OO (2017) Mechanisms of action of plant growth promoting bacteria. World J Microbiol Biotechnol 33(11):197. https://doi.org/10.1007/s11274-017-2364-9

Petković H, Lukežič T, Šušković J (2017) Biosynthesis of oxytetracycline by Streptomyces rimosus: past, present and future directions in the development of tetracycline antibiotics. Food Technol Biotechnol 55(1):3

Priya E, Thenmozhi R, Nagasathya A, Kumar DP, Thajuddin N, Muralitharan G (2017) Antagonistic potential of Streptomyces flavomacrosporus GACMPT-57 against plant pathogens. J Microbiol Biotechnol Res 4(1):68-73

Rath S, Fostier AH, Pereira LA, Dioniso AC, de Oliveira Ferreira F, Doretto KM, Maniero L, Viera A, de Oliveira Neto OF, Dal Bosco SM (2018) Sorption behaviors of antimicrobial and antiparasitic veterinary drugs on subtropical soils. Chemosphere 214:111-122

Robles-Hernández L, Hernández-Huerta J, González-Franco A, Hernández-Rodríguez O, Núñez-Barrios A, Pérez-Leal R (2015) Streptomyces PRIO41 as plant growth promoter of jalapeño pepper plants and as biocontrol agent of Fusarium. Phyton (Buenos Aires) 84(2):253-261

Romero-Rodríguez A, Maldonado-Carmona N, Ruiz-Villafán B, Koirala N, Rocha D, Sánchez S (2018) Interplay between carbon, nitrogen and phosphate utilization in the control of secondary metabolite production in Streptomyces. Antonie Van Leeuwenhoek:1-21

Ruzzi M, Aroca R (2015) Plant growth-promoting rhizobacteria act as biostimulants in horticulture. Sci Hortic 196:124-134

Sadeghi A, Karimi E, Dahaji P, Javid M, Dalvand Y, Askari H (2012) Plant growth promoting activity of an auxin and siderophore producing isolate of Streptomyces under saline soil conditions. World J Microbiol Biotechnol 28(4):1503-1509. https://doi.org/10.1007/ s11274-011-0952-7

Safari M, Amache R, Esmaeilishirazifard E, Keshavarz T (2014) Microbial metabolism of quorum-sensing molecules acylhomoserine lactones, $\gamma$-heptalactone and other lactones. Appl Microbiol Biotechnol 98(8):3401-3412

Schroth MN, Cho JJ, Green SK, Kominos SD (2018) Epidemiology of Pseudomonas aeruginosa in agricultural areas. J Med Microbiol 67(8):1191-1201

Selvakumar G, Panneerselvam P, Ganeshamurthy AN (2014) Diversity utility and potential of actinobacteria in the agro-ecosystem. In: Maheshwari DK (ed) Bacterial diversity in sustainable agriculture. Vol 1. Springer, pp 23-40

Shekh M, Naim A (2017) Isolation and characterization of antibacterial metabolites from Streptomyces species. Daffodil International University

Shrivastava P, Kumar R (2018) Actinobacteria: eco-friendly candidates for control of plant diseases in a sustainable manner new and future developments in microbial biotechnology and bioengineering. Elsevier, pp 79-91

Sivapragasam S, Deochand DK, Meariman JK, Grove A (2017) The stringent response induced by phosphate limitation promotes purine salvage in Agrobacterium fabrum. Biochem 56(43):5831-5843

Som NF, Heine D, Holmes N, Knowles F, Chandra G, Seipke RF, Hoskisson PA, Wilkinson B, Hutchings MI (2017) The MtrAB two-component system controls antibiotic production in Streptomyces coelicolor A3 (2). Microbiol 163(10):1415-1419

Sousa JAJ, Olivares FL (2016) Plant growth promotion by Streptomycetes: ecophysiology, mechanisms and applications. Chem Biol Technol Agric 3(1):24
Stover C, Pham X, Erwin A, Mizoguchi S, Warrener P, Hickey M, Brinkman F, Hufnagle W, Kowalik D, Lagrou M (2000) Complete genome sequence of Pseudomonas aeruginosa PAO1, an opportunistic pathogen. Nature 406(6799):959

Takano H, Toriumi N, Hirata M, Amano T, Ohya T, Shimada R, Kusada H, Amano S-i, Matsuda K-i, Beppu T (2016) An ABC transporter involved in the control of streptomycin production in Streptomyces griseus. FEMS Microbiol Lett 363(14)

Thanapipatsiri A, Gomez-Escribano JP, Song L, Bibb MJ, Al-Bassam M, Chandra G, Thamchaipenet A, Challis GL, Bibb MJ (2016) Discovery of unusual biaryl polyketides by activation of a silent Streptomyces venezuelae biosynthetic gene cluster. ChemBioChem 17(22):2189-2198

Tiwari P, Singh JS (2017) A plant growth promoting rhizospheric Pseudomonas aeruginosa strain inhibits seed germination in Triticum aestivum (L) and Zea mays (L). Microbiol Res 8(2):73-79

Tokala RK, Strap JL, Jung CM, Crawford DL, Salove MH, Deobald LA, Bailey FJ, Morra M (2002) Novel plant-microbe rhizosphere interaction involving Streptomyces lydicus WYEC108 and the pea plant (Pisum sativum). Appl Environ Microbiol 68(5):2161-2171

Tom V, Sarah L, Stien B, Martine M, Sofie G (2016) Streptomyces as a plant's best friend? FEMS Microbiol Ecol 92(8):fiw119

Toumatia O, Compant S, Yekkour A, Goudjal Y, Sabaou N, Mathieu F, Sessitsch A, Zitouni A (2016) Biocontrol and plant growth promoting properties of Streptomyces mutabilis strain IA1 isolated from a Saharan soil on wheat seedlings and visualization of its niches of colonization. South Afr J Bot 105:234-239

Tsujimoto M, Yoshida A, Shimizu T, Tomita T, Ohnishi Y, Kuzuyama T, Nishiyama M (2016) Aspartate kinase involved in 4-hydroxy-3nitrosobenzamide biosynthesis in Streptomyces murayamaensis. Biosci Biotechnol Biochem 80(11):2255-2263

Tyc O, Song C, Dickschat JS, Vos M, Garbeva P (2017) The ecological role of volatile and soluble secondary metabolites produced by soil bacteria. Trends Microbiol 25(4):280-292

van Dissel D, Claessen D, van Wezel GP (2014) Morphogenesis of Streptomyces in submerged cultures. Adv Appl Microbiol 89:1-45

Ventura M, Canchaya C, Tauch A, Chandra G, Fitzgerald GF, Chater KF, van Sinderen D (2007) Genomics of Actinobacteria: tracing the evolutionary history of an ancient phylum. Microbiol Mol Biol Rev 71(3):495-548

Verma V, Singh S, Prakash S (2011) Bio-control and plant growth promotion potential of siderophore producing endophytic Streptomyces from Azadirachta indica A. Juss. J Basic Microbiol 51(5):550-556

Vijayabharathi R, Sathya A, Gopalakrishnan S (2015) Plant growthpromoting microbes from herbal vermicompost plant-growthpromoting rhizobacteria (PGPR) and medicinal plants. Springer, pp 71-88

Zhang J, Yan Y-J, An J, Huang S-X, Wang X-J, Xiang W-S (2015) Designed biosynthesis of 25-methyl and 25-ethyl ivermectin with enhanced insecticidal activity by domain swap of avermectin polyketide synthase. Microb Cell Factories 14(1):152

Zhang Y, Lin C-Y, Li X-M, Tang Z-K, Qiao J, Zhao G-R (2016) DasR positively controls monensin production at two-level regulation in Streptomyces cinnamonensis. J Ind Microbiol Biotechnol 43(12): 1681-1692

Zhang H, Li X, Yang Q, Sun L, Yang X, Zhou M, Deng R, Bi L (2017) Plant growth, antibiotic uptake, and prevalence of antibiotic resistance in an endophytic system of Pakchoi under antibiotic exposure. Int J Environ Res Public Health 14(11):1336 